\title{
How Well do They Self-regulate? A Case Study of Two Undergraduate Students' Self-regulated Learning in a Telecollaborative Flipped Classroom
}

\author{
Jelena Marjanovic
}

\begin{abstract}
This paper presents case studies of two undergraduate learners studying to become primary school teachers. The qualitative analysis focused on their self-regulated learning (SRL) in a highly demanding technology-enhanced university course employing an instruction model that combines flipped classroom and telecollaboration. The study aimed to identify problems they face in each of the three phases of Zimmerman's model of self-regulated learning: forethought, performance and self-reflection. The data was collected using an online questionnaire, self-made screen recordings of students' work on tasks, snapshots of their use of Trello for work organization and recordings of online Skype meetings. Several problems were found in all the three phases of students' SRL. The paper presents these problems and discusses possible causes and solutions that can help improve the course that is the context of this study as well as similar technology-enhanced courses.
\end{abstract}

Index Terms-Autonomous learning, flipped classroom self-regulated learning, technology-enhanced learning, telecollaboration.

\section{INTRODUCTION}

New technologies have brought many possibilities for fostering autonomous learning both in and out of classroom. As a result, nowadays, there is a proliferation of technology-enhanced school courses that require students to work more independently from teacher than before. For example, many courses employ the flipped classroom model in which course content is delivered to students online instead of in the classroom, which means that in order to succeed in the course students need to be able to do all the activities at a required pace at home, without direct tutor supervision.

Such instruction models necessitate good self-regulatory skills from students without which they can hardly successfully complete those tasks that demand more independent work from them. However, self-regulatory skills are rarely taught in formal education settings and since many students have not acquired them elsewhere in life they consequently struggle in courses where their academic success depends on their ability to self-regulate their learning. In fact, the importance of self-regulated learning (SRL) goes

Manuscript received January 27, 2018; revised May 20, 2018. This work was supported by the Konect project (www.konectproject.com) under Grant EDU2013-43932-P funded by the Spanish Ministry of Economy, Industry \& Competitivity.

Jelena Marjanovic is with the Autonomous University of Barcelona Bellaterra, Spain (e-mail: jelena.marjanovic@e-campus.uab.cat). much beyond academic success. For many, SRL skills affect their overall life satisfaction because lifelong learning, nowadays more important than ever, often depends on one's ability to utilize available technological resources effectively for their learning on their own initiative and without direct instruction [1]. That is why it is important to develop methods of encouraging students to improve their SRL in highly demanding technologically-enhanced courses, but for that to happen we first need to find out what problems prevent them from self-regulating effectively in such courses.

\section{Self-Regulation In LEARNing}

\section{A. The Concept of Self-regulation in Learning}

Self-regulation in learning is a complex construct consisting of multiple dimensions such as student metacognition, motivation and behavior [2]. Although they are related, SRL should be distinguished from autonomous learning. An autonomous learner takes full control of her or his learning, thus deciding on what to learn, as well as how, when and where to do it [3]-[6], whereas being able to self-regulate one's own learning is just one of the prerequisites for successful autonomous learning. In other words, SRL is a narrower concept than autonomous learning. Learning can be highly self-regulated and yet not autonomous (e.g. the learner has no control over the task or learning content but needs to engage in SRL to complete it), whereas autonomous learning cannot happen without self-regulation.

SRL "involves cognitive, affective, motivational and behavioral components that provide the individual with the capacity to adjust his or her actions and goals to achieve the desired results in light of changing environmental conditions" [7]. When executing tasks, highly self-regulated students set appropriate goals, employ adequate learning strategies, manage their time effectively, self-monitor and self-evaluate, seek assistance from appropriate persons or sources and in general organize and manage their learning processes [8].

\section{B. Related Concepts}

A number of concepts have been described as related to SRL in the pertinent literature. Self-efficacy (SE) is one of them. Students with high SE believe in their competence to take all the necessary decisions and actions to complete tasks successfully and achieve desired outcomes [9]. A positive relationship between SE and SRL has been found in [10], [11] in [7] it is argued that learners need to have high SE in order to be able to self-regulate their learning.

Another concept that can be related to SRL is perceived 
academic control (PAC). PAC refers to learners' subjective perception of their influence over their academic outcomes. In other words, learners with high PAC have a high sense of control over their academic success. Central to PAC are primary (PC) and secondary control (SC). In the academic context, $\mathrm{PC}$ is learner ability to influence external factors that are important for academic success, such as one's environment and other circumstances of one's learning. Therefore, a student who perceives her or his PC as high believes that she or he is fully in control over her or his study outcomes. The other related construct, SC, refers to perception of one's control over her or his internal states that influence academic outcomes. A high SC generally indicates learner's ability to adapt their cognitive processes, emotional states and strategical approaches to any circumstances in order to attain the desired academic outcome [12]. The role of perceived control over academic outcome in SRL has been recognized as a significant factor that affects SRL [8], [13], [14]. In [12] the positive relationship between PC, SC and SRL was confirmed by finding that high perceived student control leads to greater responsibility and therefore also to a more proactive and self-directed approach to one's learning reflected in taking actions and initiating processes typical of self-regulated learners.

\section{SRL in Technology-Enhanced Interactive Learning Environments}

Technology-enhanced learning environments are seen as holding great potential for fostering SRL [1], [15]-[17]. In [17] students' intrinsic motivation in computer-assisted language learning (CALL) was investigated and it was found that it was positively affected by students' freedom to regulate and organize their own learning, and therefore personalize the learning content. In particular, interactivity of an online learning environment has been identified as a predictor of SRL [16], [18]-[20]. It was found that in a blended computer programming course, student satisfaction with the interactivity and usefulness of the online mode positively affected their SRL [19]. In other studies, a connection between telecollaboration and autonomy development was drawn on emphasizing that student interaction can be organized in a way that fosters autonomy [21], [22]. The benefits that technology-enhanced interactive environments have for developing autonomous learning including self-regulation are also discussed in [23]. In [24], group autonomy in telecollaborative learning of pre-service teachers was explored and it was found that the group performed exceptionally well in regulating the task execution, e.g. making sure that it is completed before the deadline. Another study found that students conducting researching in collaboration with their peers and using digital tools resulted in acquisition of new strategies. beneficial for learning English such as exploring different learning resources [25]. However, researchers also stress that technology alone, although undoubtedly having a significant role, is not sufficient for fostering SRL and we should not rely on it to increase SRL by default [15].

\section{Zimmerman's Model for Researching SRL}

One of the most widely used models for research on SRL is the one proposed by Zimmerman [26]. The cyclical model focuses on the SRL processes that occur in the following three phases:

1) Forethought: the preparation phase, i.e. task analysis that students engage into before performing a task (e.g. development of strategic approach, setting goals, etc.), which is affected by self-motivational beliefs such as self-efficacy, intrinsic interest in task, goal and outcome expectations.

2) Performance: processes such as employing appropriate learning strategies and keeping attention focused on the task (strategy use processes) as well as metacognitive and physical self-monitoring, which belong to self-observation processes.

3) Self-reflection: processes such as evaluating learning outcomes and attributing them to causes (self-judgement) and consequent adaptive behaviour (self-reactions). The latter refers to positive adaptation such as finding a better strategy when the existing one fails but also negative adaptation such as procrastination, feeling disengaged, helpless, etc.

All the three phases of the described model are interdependent and problems in one phase negatively affect all the processes from the other two phases as well. To illustrate, a learner might fail to develop an effective strategic plan for a task execution because she or he feels incapable of good work organization. On top of that, the learner might not be intrinsically motivated to work on the task in the first place (forethought phase). As a consequence, the learner might struggle to keep her or his attention focused on the task or fail to keep a record of her or his progress since in the forethought phase she or he has not thought strategically about the desired goals, steps that need to be taken and methods to be used. This lack of attention leaves her or him with no clear basis for self-monitoring (performance phase). As a result, the learner might experience a number of self-reactions, such as attributing her or his poor SRL to a too difficult task or lack of study skills. The learner might also experience some negative feelings such as disengagement from the task or they might react more positively by recognizing the need for a more appropriate strategy and acting upon it (self-reflection phase). These self-reactions and self-judgement might consequently influence the forethought phase, e.g. the learner's interest in the task and self-motivation beliefs may drop even lower, or increase, if the learner has reacted positively to the obstacles in her or his SRL. This further affects the performance phase, which then influences the self-reflection, and so on. In that manner, a repetitive cycle is established.

\section{ThE PRESENT STUDY}

\section{A. The Context of the Study}

The setting of the present study is a final-year undergraduate teacher education course based on a model combining flipped classroom and telecollaboration (online interactive exchanges) between Spanish/Catalan and USA students at Autonomous University of Barcelona (UAB) in Spain. The course has been implemented every academic year since 2003 [27]. It is highly intense and requires a lot of independent work from the course students (future primary 
school teachers). Besides the heavy workload, the students are also challenged by having to communicate in English, a foreign language (whereas their native language is Spanish or Catalan). However, what makes this context most peculiar is the political turmoil that occurred in Catalonia at the time of its implementation and considerably affected the face-to-face component of the blended teacher education course. Namely, the classes were supposed to be held once a week, but due to the protests that coincidentally always happened on the same day of the week, they had to be cancelled altogether on a few occasions. In addition, the classes coincided with two public holidays so in the end only 9 out of 15 planned classes were held. Considering the classes were originally planned as very long sessions ( 3.5 hours) in which a considerable amount of activities would have been implemented, a lot of content ended up not being addressed. This also meant many lost opportunities for clarifying any concerns students might have had about the telecollaboration project.

\section{B. The Participants}

Two female students (volunteers) were selected as participants. The author opted for studying the two cases only to acquire holistic and in-depth insights into each student's SRL. The students, Maria and Gemma (pseudonyms), are Catalan and are 21 years old. They both show traits of highly autonomous learners. For example, using Internet technologies, they have created their own personal learning environments for out-of-university study. Maria is learning how to become a make-up artist by watching YouTube videos and attending online courses, whereas Gemma uses a combination of self-selected online resources and mobile phone apps (e.g. Duolingo) to enhance her English competence.

\section{Data Collection and Analysis Process}

The aim of the study was to analyze and identify the problems that the two students experience with their SRL in the highly demanding teacher education course. This topic had emerged in a previous analysis of the students' autonomous learning in the course. Namely, the students had participated in a project in which their autonomous learning was investigated. The preliminary results revealed that both students have been successfully engaged in self-initiated and self-directed out of classroom learning but they struggle to self-regulate the independent learning required from them in the teacher education course. That is where the interest in exploring the problems they experience in SRL in this context originated from. The research questions that guided the study are: 1). Which phase (forethought, performance or self-reflection) do the students experience most problems with? 2). What are the most critical problems they face in each phase?

The data was collected over a 4-month period using the following instruments: an online questionnaire, self-made screen recordings of student work on course tasks, snapshots of students' activity on Trello - a digital tool that they were asked to use for planning their studying, and recorded online interviews (conducted via Skype once a month on average).

The data collection consisted of 3 phases. In the first phase, the students filled in an online questionnaire asking them to identify the areas of their SRL they most needed and would like to work on. Their answers were subsequently triangulated and additional information obtained in two online interviews, one with each student. In these online meetings, besides elaborating on their questionnaire answers, the students gave more insights into their self-regulation processes by explaining their study habits, problems they encounter, and giving their perceptions of their own SRL. In the second phase of the project, the students were asked to record their computer screens while working on the tasks required in the teacher education course. The recordings were watched first by the researcher and then in the second interviews, which were stimulated recall (SR) interviews, they were watched again with the students asking them to describe what they were doing and why they took the recorded actions. In the third phase, the students were introduced to Trello, an app used to organize individual and team project work and were then asked to use it to organize their own work on the teacher education course tasks. The students recorded their use of Trello and gave the researcher full access to their Trello boards. The third online interview was held with both students at the same time. In it, they choose to discuss the studying habits and the education course requirements that they perceived as problematic. The meeting turned into a counselling session where the students gave each other support in the problems they both seemed to share.

To analyze the data, the recordings of all the meetings were watched and annotated for evidence of students' SRL. These episodes were then transcribed. Next, the self-recorded videos of students' work were watched and episodes of students' SRL were identified with the help of the information from the SR interviews. These episodes were turned into detailed written accounts of the actions the students took and the explanations and reasonings behind the actions elicited from the SR interviews. The interview transcripts, the written accounts of student work, the questionnaire answers and Trello snapshots were subsequently coded using Zimmerman's model. For each case, the data bits were categorized as forethought, performance or self-reflection phase.

\begin{tabular}{|c|c|c|}
\hline Forethought & Performance & Self-reflection \\
\hline $\begin{array}{l}\text { 1.Task analysis (TA) } \\
\text { - Goal setting (GS) } \\
\text { - Strategic planning } \\
\text { (StrP) } \\
\text { 2.Self-motivation beliefs } \\
\text { (SMB) } \\
\text { - Self-efficacy (SE) } \\
\text { - Outcome } \\
\text { expectation (OE) } \\
\text { - Intrinsic interest } \\
\text { (Int) }\end{array}$ & $\begin{array}{l}\text { 1.Self-control (SfC) } \\
\text { - Attention focusing } \\
\text { (AF) } \\
\text { - Task strategies (TS) } \\
\text { - Self-instruction (SI) } \\
\text { 2.Self-observation: (SfO) } \\
\text { - Metacognitive } \\
\text { - } \text { mentoring (Mtcg) } \\
\text { - Self-recording (SfRec) }\end{array}$ & $\begin{array}{l}\text { 1.Self-judgements (SJ)| } \\
\text { - Self-evaluating } \\
\text { - } \text { Attributinance(SfEp) } \\
\text { significance to the } \\
\text { outcome: positive (+Atrib) } \\
\text { + negative (-Atrib) } \\
\text { 2.Self-reactions (SfReac) } \\
\text { - Self-satisfaction (SfSts) } \\
\text { - Adaptive (defensive) } \\
\text { inference: } \\
\text { positive (+Adapt), } \\
\text { negative (-Adapt) }\end{array}$ \\
\hline
\end{tabular}

Each data bit illustrated one or mostly more than one SRL processes described in Zimmerman's model. They were coded using the hierarchical coding system shown in Table I.

The coding process was not completely straightforward as some identified processes could be coded with more than one code. For example, student procrastination could be sometimes interpreted both as an attention focusing issue and 
a negative adaptive inference (student's reaction to her unsatisfactory performance). When all the data had been triangulated, categorized and coded, the two cases were compared to identify problems that were repetitive and common for both students.

\section{FINDINGS AND DISCUSSION}

Overall, despite showing some traits of autonomous learners, both students experience a number of problems in all three phases of their SRL (forethought, performance and self-reflection). The most critical ones will be presented in the following paragraphs.

\section{A. Forethought}

On the forethought level, the most critical problems that were found can be ascribed to students' self-efficacy, goal setting and strategic planning processes. During the online meetings, both students reiterated their dissatisfaction with the role of "experts" given to them by their tutor in task completion (e.g. when they needed to decide on an action plan or select a definition to use). They do not believe themselves capable of performing such "expert" self-regulatory actions and are afraid of making wrong decisions, which indicates low self-efficacy. As Gemma put it:

When someone tells me: "Now you are an expert and you will solve others ' problems. ", I think: "Whatever." I don't see myself as an expert at all. Maybe it works with children because they get all like: "Yey I'm an expert!", but it I'm not a kid and I'm not fooled by that. I know what an expert is and I am not one.

This finding is hardly surprising considering these students have not often been required to engage in autonomous learning in their formal education thus far and therefore might incorrectly perceive high self-regulatory skills as an exclusive prerogative of experts (not necessarily teachers). This finding indicates that we should investigate more into the misconceptions students have about self-regulation and to work on eradicating them. For example, teachers can show they also struggle with SRL by sharing their experience and advice on how to overcome obstacles in SRL. If an on-going discussion of SRL is established in classroom, it may help eliminate the intimidation some students feel when faced with SRL.

Gemma showed particularly low level of self-efficacy. For example, for her a major obstacle to completing tasks such as summarizing an article is her lack of confidence in her ability to understand and to summarize texts efficiently. This self-doubt becomes reinforced when she fails to effectively plan her learning and set realistic goals. To illustrate, she would bring all the assignments for a given week to the library, planning to finish them all in one day, only to end up feeling demotivated and unproductive upon realizing she has not done much. As a diligent student, she does recognize the importance of task execution planning and invests effort into it but shows lack of strategic thinking. More specifically, she identifies strategic planning with making a to-do list, which is just one component of a strategic approach among many other such as breaking down tasks into small manageable steps [9]. This could be observed in the screen recordings and snapshots of Gemma's work, as well - she dedicated considerable time to creating elaborated to-do lists in Trello but did not divide her tasks into small manageable steps that would facilitate their execution. It can be concluded that the potential of digital tools to foster student SRL that some authors describe [17] has not been exploited by this student due to her lack of strategic thinking, which is in line with Bartolome and Steffens who argue that employing technology per se does not guarantee success in promoting SRL.

Gemma's struggle with setting realistic goals and strategically planning her learning can be connected to her low SE. According to reference [10], low SE prevents students from perceiving challenging tasks as opportunities for learning. Students with low SE feel intimidated by more demanding tasks or heavier workload and as a consequence fail to set appropriate goals [20]. In other words, low self-efficacy causes inability to set realistic goals. However, we should also consider the opposite direction in which setting unmanageable objectives affects student SE. In case of Gemma, the realization that her study goals are unrealistic undermines her self-confidence, which in turn impairs her ability to see the task clearly and not as a threat, creating, in her words, a "vicious circle" (which interestingly corresponds to Zimmerman's cyclical view of SRL processes). Therefore, if we want to help students increase their SE, we should focus on teaching them how to strategically plan theirlearning.

In the case of Maria, there is a mismatch between her perception of her strategic planning abilities and her actual planning. On various occasions, she has reported generally having no issues with her work organization as she would always set realistic goals and even add extra time for their completion to account for unpredictable situations. She calls herself "radical" - when she sets a deadline she does not allow herself to exceed it. However, like Gemma, when describing her planning she strictly refers to her ability to make a realistic to-do list. In Trello, she planned her task execution by creating a general overview of tasks to be done but did not divide them into smaller steps nor assigned any deadlines. When asked about this in the meetings Maria stated she was satisfied with her planning system and that it worked well for her, and that it was her ability to stick to her plans that she saw as problematic. Similarly to Gemma's case, this indicates a lack of awareness of what strategic planning means and how it affects the other phases of studying, with the difference that in Maria's case it resulted in overconfidence and a mismatch between her SE beliefs and her actual self-regulation. Iwamoto et al [28] found that the undergraduate students fail to adapt to the university level standard of SR despite their ambitions to succeed because they continue to apply the study skills that worked for them in the lower levels of education but are not sufficient for a more challenging environment such as university. The students were simply unaccustomed to thinking of SR skills as indicators of academic success as they might, for example, postpone studying to the moment before test and still score well.

Similarly, Maria's lack of awareness of the processes that strategic planning entails can be rooted in her belief 
(reiterated in the meetings) that what makes her a good student are her good grades (as opposed to her study skills). However, it is difficult to make this connection with certainty because of the previously described peculiar setting of this study. The facts that it is her final year of studies, the language of instruction is a foreign language and the course itself, already intense, could not be held regularly due to the political turmoil are factors that make comparison to other similar studies difficult. Having said that, a conclusion can be drawn that if SRL skills were assessed in schools along with knowledge, students might be more incentivized to work hard on attaining them. Again, this stresses the need to coach SRL skills, as to assess them, we need to teach them first. There have been suggestions to include the subject of SRL in official curricula [29] but until that happens (if it happens), teachers can take the initiative to foster SRL through various activities in their courses. In the context of this study, it does not necessarily mean squeezing in SRL instruction into an already packed program. Students can be encouraged to think about SRL and find ways to improve it if they are referred to online resources, encouraged to discuss it online in their telecollaborative exchanges, required to participate in microlearning activities aimed at promoting SRL or just exposed to effective SRL strategy modelling in the classroom. A good example of digital tools that teachers can use to foster students SRL is given in [30].

\section{B. Performance}

In the performance phase, a number of problems pertaining to self-control were found. Attention focusing seems to be the most problematic area for both students, as they both reported inability to stay focused on a task even after planning it thoroughly. Both in the questionnaire and the online meetings the students described procrastination and task completion postponing as their biggest problems. However, no overt procrastination could be seen in the screen recordings of their work, which was expected as the fact they knew they were being recorded made them more self-conscious. This was confirmed in the online meetings as they said they did not procrastinate because they knew the researcher would see the video (even though they had been encouraged to show reality so that they could be afterwards advised on how to improve their study habits). This procrastination issue could be interpreted as caused by the student workload, that is already heavy as they are in their final year of studies and is further burdened by the requirements and tasks of the highly intense teacher education course. Both students reported experiencing high levels of anxiety due to the intensity of their courses and such affective factors were identified as causes of procrastination in a few studies [31]-[33] as cited in [28].

In the case of Maria, another problem is the lack of intrinsic motivation. She perceives the tasks as not useful for her as a teacher. On top of that, she is even considering choosing a completely different career after university as she realizes she enjoys learning about the make-up art much more. She shows a high level of metacognition as she recognizes that she struggles to assume responsibility for maintaining her own interest and motivation, overcoming motivation obstacles in her learning and generally enjoying learning independently with technology. Her motivation in the teacher education course is strictly to finish it, so she would employ effective self-regulation strategies such as cheering herself to motivate herself to work on tasks ("Come on Maria, only 9 months left until the end"). The lack of motivation is also probably a likely cause for her procrastination, besides the aforementioned factors of course intensity and heavy workload. She particularly struggles to see sense in telecollaboration and how she as a teacher can benefit from interacting with American students online. This contradicts studies that found that highly interactive technology-enhanced environments had a vital role in increasing student perception of usefulness and were conducive to SRL. [12], [17], [19]. Reference [22] suggests that if telecollaboration is set up appropriately it can lead to development of learner autonomy. In [20] a blended setting similar to the one analyzed in this study was investigated and the positive relationship between online learning environment interactivity and student SRL was confirmed. In [25], collaborative work was described as conducive to group autonomy, in particular self-regulative activities. Others have found a positive effect technology-enhanced learning environments have on learner autonomy and self-regulation [18], [24], [27]. It might seem that telecollaboration have not had the same positive effect on Maria's SRL and perception of the course usefulness. This could entail that being able to engage in social interaction alone is not sufficient to motivate students to participate proactively in telecollaboration as they need to also see clear relevance and usefulness to it. However, it is difficult to identify this as a crucial factor that undermines Maria's motivation since she has already expressed little interest in becoming a teacher.

\section{Self-reflection}

In the third phase of Zimmerman and K's model, a combination of negative attribution and defensive inference was found to be impairing students SRL. On the one hand, both students show high levels of responsibility for their own learning which is best exemplified by their ongoing out-of-classroom self-directed learning. They seem to understand they can take a proactive approach to improve their academic success and career prospects as they have both created their own personalized learning environments. On the other hand, in the context of the teacher education course, they mostly attribute their problems with sticking to their plans and schedules to uncontrollable variables, specifically, in the amount of university work they have. This negative attribution in form of defensive inferences could beobserved in both students: helplessness, cognitive disengagement, even apathy.

On the self-judgement level, Maria shows awareness of her responsibility for not always self-regulating successfully but mostly attributes obstacles in her SRL to a lack of motivation caused by external, uncontrollable factors. For example, she ascribes instances of poor self-regulation to insufficient tutor guidance, headache, ineffective task structure and generally seeing no use in the course tasks. Similarly, Gemma takes responsibility for her SRL and analyzes it metacognitively. However, although she is able to identify what prevents her from performing to her 
satisfaction, she finds it difficult to change as it is a part of her "nature". She calls herself a perfectionist and experiences despair as she does not see a solution to that problem. This "perfectionism" prevents her from sticking to her study plans and schedules and interferes with her time management. An interesting account given by Gemma illustrates this problem well. Namely, her father, having noticed her negative feelings caused by struggling with completing the tasks on time, proposed a solution: they would come up with a deadline for each task and she would have to stop working regardless of whether she had finished the task. The father would monitor her to make sure she had indeed stopped working at the agreed time. Gemma apparently accepted that arrangement but felt so anxious upon realizing she would not have enough time to do the task "perfectly" that she resorted to deliberately not reporting all the tasks to her father so that she could distribute the limited time to fewer tasks and thus have more time to do them thoroughly. Needless to say, the results did not change much - there were still many unfinished tasks and uncompleted to-do lists. Several instances observed in the screen recordings of Gemma's work could be interpreted as this "perfectionism" issue. For example, one such episode shows her reviewing a document produced in collaboration with her group. During the whole episode that lasted 5 minutes she wrote, deleted and rewrote around 5 versions of a comment just a few lines long that expressed her agreement with an idea proposed in the file. She explained that she feels great responsibility for her part in the group project and hence tries to give "perfect" feedback.

Besides her nature, Gemma also attributes her problems in SRL to the heavy workload the students need to cope with in the teacher education course and in their final university year in general, as well as the educational system that does not encourage autonomous learning ("I don't think I can summarize or get the most important ideas from texts, I haven't been taught to do that."). In [9] the authors argue that attributing one's own failure to attain learning goals to factors that are outside of one's control or are perceived as unchangeable is an indicator of poor self-regulation. These findings also align with [13] where the influences of primary and secondary student control (PC and SC) was studied and it was found that both predicted student SRL. In other words, those students who believed they had control over their learning process and outcomes also felt more responsible for their own success or failure to achieve learning goals and therefore were more able to act on this responsibility and self-regulate better. In this study, both students feel responsible for their SRL but do not feel able to change the problems they experience in it. Moreover, they also focus on external variables that are out of their control. The question that arises from these findings is how to help students avoid perceiving the factors such as a particular school system, course, teacher, etc. for their unsatisfactory academic outcomes without discouraging them from being constructively critical towards the same factors. Students need to know where the responsibility of the school ends and theirs begin so that neither can be underplayed.

This becomes especially important in the contexts such as the one studied here, where unforeseen and uncontrollable circumstances, such as political instability in a country, put additional stress on already stressed students and thus require them to self-regulate their learning more than it can be reasonably expected. Admittedly, assessing students' SRL in such a context is complicated. This study therefore entails that research on SRL should be accompanied with an in-depth analysis of the context in which it is done to account for all controllable and uncontrollable variables that affect student SRL.

\section{LIMITATIONS AND FUTURE STUdiES}

The focus of this study is on providing an in-depth insight into SRL of students in a telecollaborative blended teacher-education course at a Spanish university which means that the context is highly situated and the extent to which this the findings can be generalized is limited, especially if one considers the political turmoil that severely affected the course organization at that moment. If repeated in more regular circumstances, some results might differ to a certain extent. Next, only two cases were analyzed, but some future studies might look into multiple cases from the same or different courses or even universities and make comparisons between them. Also, a more varied participant profile could be chosen in future research as this study focused on two female participants who can both be described as autonomous and academically successful. Finally, this study could be complemented with a quantitative insight into SRL of a much higher number of students.

\section{CONCLUSION}

This study investigated the problems that two undergraduate students experience in their SRL in a highly demanding technology-enhanced teacher education course. All the three phases of SRL processes were explored: forethought, performance and self-reflection [9], [26]. In each phase, several problems that impede the students' SRL were found. In the forethought phase, both students experience problems with their self-efficacy, as well as strategic task execution planning. They do not consider themselves "experts" enough to engage in autonomous learning and have shown some misconceptions about SRL that probably stem from lack of experience with autonomous learning in their formal education. Despite their low confidence in their ability to learn autonomously, both students show many traits of autonomous learners since they regularly engage in informal learning activities in order to achieve personal academic and career goals. Although the students show awareness of the importance of the forethought in SRL, in practice their use of strategy for task planning is limited. For example, neither student would break their tasks into small manageable steps when planning it. Employing technology (Trello app) did not lead to a better strategic approach to task planning. When it comes to self-motivational beliefs, it seems that the telecollaboration with the US students did not have the expected positive effect on student intrinsic motivation in completing the tasks and therefore on their SRL but this might, to some degree, be attributed to the peculiar circumstances in which it was 
conducted (irregular classes, high level of stress due to political turmoil, heavy workload and approaching end of final university year).

On the performance level, both students struggle with procrastination which can be linked to two factors: the anxiety (caused by the heavy workload, course intensity and approaching end of the final university year) and the lack of intrinsic motivation in Maria's case. Maria is questioning her decision to become a primary school teacher and is more inclined to consider a completely different career path. Therefore, she does not see the course as useful and relevant and she recognizes it is probably preventing her from focusing her attention on completing the tasks on time.

When it comes to self-reflection, the students feel partially responsible for their problems with SRL. Gemma expressed guilt for not having "learnt to be more autonomous by her final university year" and for always spending too much time on tasks trying to do them "perfectly", whereas Maria admitted she should be more disciplined when completing tasks and know how to resist the urge to watch movies and do other activities that distract her from work. However, they do not recognize how they could change them and thus improve their SRL. On top of that, the students ascribe their problems in SRL to fixed variables such as the heavy workload and the educational system that does not traditionally encourage autonomous learning. However, it is hard to say whether the same negative attribution would have been found if the course had been held regularly. i.e. if there had not been the political turmoil that significantly affected the course.

In conclusion, the whole self-regulation cycle that Zimmerman described in his model was observed in these two student cases. The study focused only on the problems they experience in SRL, hence a "vicious cycle" (in words of one Gemma) is described. In it, the low SE and lack of intrinsic motivation from the forethought cause problems in the performance phase, such as procrastination and spending too much time on a task, which are then in the self-reflection phase attributed to uncontrollable factors of lack of study skills or unsatisfactory educational system. This causes negative feelings such as helplessness, apathy and despair which further negatively impact the students' SE and motivation on the forethought level and so the cycle continues. The way to break the cycle in this specific case is to raise students' awareness of self-regulation processes and coach them on concrete strategies that facilitate SRL. In highly intense and demanding courses such as the one studied here, it is unlikely that including self-regulation skills into the curriculum is realistically possible. However, in such situations teachers can have a crucial role as they can model effective SRL, share their personal experience and strategies and thus trigger an on-going discussion of SRL in the classroom.

\section{ACKNOWLEDGMENT}

The author would like to thank Gemma and Maria, the two student participants of the study for taking part in this study despite their hectic schedules. The author feels especially obliged to Dr Melinda Dooly, her PhD supervisor, for providing invaluable feedback on this paper and support during the project.

\section{REFERENCES}

[1] J. Beishuizen, K. Steffens, "A conceptual framework for research on self-regulated learning," Self-Regulated Learning in Technology Enhanced Learning Environments. Technology Enhanced Learning, Sense Publishers, 2011.

[2] B. J. Zimmerman, "Models of self-regulated learning and academic achievement," Self-regulated Learning and Academic Achievement.Theory, Research and Practice, New York: Springer, pp. $1-25$.

[3] H. Holec, Autonomy and Foreign Language Learning, Oxford: Pergamon Press, 1981.

[4] D. Nunan, "Closing the gap between learning and instruction," TESOL Quarterly, vol. 29, pp. 133-158, 1995.

[5] D. Little, Learner Autonomy 1: Definitions, Issues and Problems, Dublin: Authentik, 1991.

[6] W. Littlewood, "Autonomy: An anatomy and a framework," System, vol. 24, pp. 427- 435, 1996.

[7] M. Zeidner, M. Boekaerts, and P. Ointrich, "Self-regulation. Directions and challenges for future research," Handbook of Self-regulation, New York: Academic Press, 2000, pp. 749-768.

[8] B. J. Zimmerman and A. Kitsantas, "The hidden dimensions of personal competence: Self-regulated learning and practice," Handbook of Competence and Motivation, New York: Guilford, 2005.

[9] A. Bandura, Self-efficacy: The Exercise of Control, New York: W. H. Freeman, 1997.

[10] R. Lynch and M. Dembo, "Online learning in a blended learning context," International Review of Research in Open and Distance Learning, vol. 5, 2004.

[11] S. Sharma, G. Dick, W. W. Chin, and L. Land, "Self-regulation and e-learning," in Proc. the Fifteenth European Conference on Information System, St Gallen: University of St. Gallen, pp. 383-394, 2007.

[12] E. J. Fishman, "With great control comes great responsibility: The relationship between perceived academic control, student responsibility, and self-regulation," British Journal of Educational Psychology, vol. 84, pp. 684-702, 2014.

[13] E. A. Skinner, J. G. Wellborn, and J. P. Connell, "What it takes to do well in school and whether I've got it: A process model of perceived control and children's engagement and achievement in school," Journal of Educational Psychology, vol. 82, pp. 1990.

[14] S. L. Stockdale and R. G. Brockett, "Development of the PRO-SDLS: A measure of self-directionin learning based on the personal responsibility orientation model," Adult Education Quarterly, vol. 61, pp. 161-180, 2011.

[15] A. Bartolome and K. Steffens, "Technologies for self-regulated learning," Self-Regulated Learning in Technology Enhanced Learning Environments A European Perspective, Rotterdam: Sense Publishers, 2011, pp. 21-33.

[16] H. Zhao, "Factors influencing self-regulation in e-learning 2.0: Confirmatory model factor," Canadian Journal of Learning and Technology, vol. 42, pp. 2-20, 2016.

[17] E. Ushioda, "Tandem language learning via e-mail: From motivation to autonomy," ReCALL, vol. 12, pp. 121-128, 2000.

[18] S. S. Liaw and H. M. Huang, "Perceived satisfaction, perceived usefulness and interactive learning environments as predictors to self-regulation in e-learning environments," Computers \& Education, vol. 60, pp. 14-24, 2013.

[19] H. Cigdem, "How does self-regulation affect computer-programming achievement in a blended context?" Contemporary Educational Psychology, vol. 6, pp. 19-37, 2015.

[20] R. Carneiro and A. M. V. Simão, "Technology enhanced environments for self-regulated learning in teaching practices," Self-Regulated Learning in Technology Enhanced Learning Environments A European Perspective, Rotterdam: Sense -Publishers, 2011, pp. 75-103.

[21] M. Dooly, "Constructing knowledge together," Telecollaborative Language Learning. A Guidebook to Moderating Intercultural Collaboration Online, Bern: Peter Lang, 2008, pp. 21-43.

[22] M. Dooly, "Telecollaboration," The Handbook of Technology in Second Language Teaching and Learning, Hoboken, NJ: Wiley, pp. 169-183, 2016.

[23] K. Schwienhorst, Learner Autonomy and CALL Environments, New York: Routledge, 2007.

[24] F. Mangenot and E. Nissen, "Collective activity and tutor involvement in e-learning environments for language teachers and learners," Calico Journal, vol. 23, pp. 601-622, 2006. 
[25] M. Warschauer and R. Kern, Network-Based Language Teaching. Concepts and Practice, Cambridge, MA: Cambridge University Press, 2000.

[26] B. J. Zimmerman, "Attainment of self-regulation: A social cognitive perspective," Self-regulation: Theory, Research and Applications, Orlando FL: Academic Press, 2000, pp. 13-39.

[27] R. Sadler and M. Dooly, "Twelve years of telecollaboration: What we have learnt," ELT Journal, vol. 70, 2016, pp. 401-413, 2016.

[28] D. H. Iwamoto, J. Hargis, R. Bordner, and P. Chandler, "Self-regulated learning as a critical attribute for successful teaching and learning," International Journal for the Scholarship of Teaching and Learning, vol. 11, pp. 1-10, 2017.

[29] A. M. V. Simão, F. C. Duarte, and P. C. Ferreira, "Self-regulated learning in technology enhanced environments: Perspectives and practices," presented at the European Conference on Educational Research, University of Goteborg, 10-12 September 2008.

[30] D. Lenne, M. Abel, and P. Trigano, "Technological tools to support self-regulated learning," Self-Regulated Learning in Technology Enhanced Learning Environments A European Perspective, Rotterdam: Sense -Publishers, 2011, pp. 123-135

[31] A. J. Onwuegbuzie, 'Academic procrastination and statistics anxiety," Assessment and Evaluation in Higher Education, vol. 29, pp. 3-19, 2004.
[32] G. C. Rakes and K.E. Dunn, "The impact of online graduate students' motivation and self-regulation on academic procrastination," Journal of Interactive Online Learning, vol. 9, pp. 78 -93, 2010.

[33] K. Dunn, "Why wait? The influence of academic self -regulation, intrinsic motivation, and statistics anxiety on procrastination in online statistics," Innovative Higher Education, vol. 39, 33-44, 2014.

Jelena Marjanovic was born in Belgrade in 1989. She is currently a PhD candidate at the Autonomous University of Barcelona (Universitat Autonoma de Barcelona), Barcelona, Spain. The field of her studies is technology-enhanced education and her thesis focuses on autonomous technology-enhanced learning.

She holds an MPhil in Education (specializing in second language education) from the University of Cambridge, Cambridge, UK (2013). Her $\mathrm{BA}$ is in English language and literature (specializing in teaching methodology) from the University of Belgrade, Belgrade, Serbia (2012).

She is also currently working as a freelance eLearning Developer and Instructional Designer. Previously, she held the position of eLearning Developer at eFront and English Teacher at the Institute for Foreign Languages in Belgrade, Serbia. 